\title{
Training of Vancouver 2010 volunteers: a legacy opportunity?
}

\begin{abstract}
The successful delivery of a mega-sport event depends upon a volunteer workforce. It is often asserted that the training of event volunteers contributes to the creation of a social legacy via the transfer of learning to other volunteer contexts; thereby creating an enhanced volunteer pool after the event that will support the tourism and events industries in the host communities. This article reflects upon the reality of that assertion and argues that in order to achieve legacy both training and development strategies are required. As such an analysis of data collected at the Vancouver 2010 Olympic and Paralympic Winter Games around training and legacy is discussed. A Legacy Training and Development Model is offered and subsequently, applied to the case study. The article concludes by suggesting that training at Vancouver 2010 was a missed opportunity in achieving legacy.
\end{abstract}

\section{Key words:}

Training; Volunteers; Legacy; Mega Sport Events; Vancouver 2010 


\section{Training of Vancouver 2010 volunteers: a legacy opportunity?}

\section{Introduction}

Mega sport events such as the Olympics and Paralympics (the Games) create a unique opportunity to motivate governments, communities, organisations and individuals to work together to create lasting legacies. To deliver the Games, the organising committees (OCOGs) are dependent upon the contribution of thousands of volunteers, without whom bidding for and delivering the Games would be impossible. It has been suggested that 'the Olympics of today are as much a creation of the volunteers as of anyone else' (MacAloon (2000, p. 21). This was further endorsed by, John Furlong, the Vancouver Organising Committee (VANOC) CEO, reflected after the Vancouver 2010 Games, that the real heroes of the Games were the volunteers (Furlong, 2010). However, the Games' volunteers may offer more than their ability to help deliver a successful event they may be part of a change in community volunteering after the Games, contributing to a volunteering legacy.

A post-Games volunteering legacy may be seen in either an increase in volunteering from existing volunteers and/or the recruitment of people new to volunteering (Dickson, Benson, Blackman, \& Terwiel, 2013). Strigas \& Newton-Jackson Jr (2003) purports that by increasing the sense of commitment of volunteer organisers the ability to offer, sustain, or even expand the quantity, quality, and diversity of an organisation's services escalates. The question is whether or not this increased commitment enhances legacy potential from an event perspective. Costa, Chalip, Green \& Simes (2006) have suggested that commitment to, and satisfaction with, the event is influenced by the training experience and how that supports the creation of community amongst the volunteers. This reflects Farrell, Johnston and 
Twynam's (1998) comment that 'volunteer satisfaction is founded upon a link between motivations and actual experience' (p. 290) where the critical link between motivation and experience is often training that is informative, enhances attachment to the organization and prepares volunteers with the right tools to fulfil their responsibilities and ultimately support legacy development.

To prepare volunteers for the Games, a range of training opportunities are provided by the OCOG. However, the extent to which training is designed to facilitate just the delivery of the event, or to support the creation of a legacy via a pool of skilled and experienced event volunteers who could support events, tourism and hospitality contexts in the future, is questionable and part of a wider legacy debate around mega sport events (Dickson, Benson \& Blackman, 2011). Consequently, if an event volunteering legacy is to be realised it will be dependent upon a range of human resource strategies including both the training (i.e. for the event) and development strategies (i.e. for legacy) that are put in place to support such an outcome, as well as the experiences of the volunteers during the event that may influence their commitment to volunteerism in the future (Dickson, Terwiel \& Benson, 2011).

The aim of this article is to offer an analysis of data collected at the Vancouver 2010 Olympic and Paralympic Winter Games in British Columbia, Canada around themes of training and legacy, where it was clear at the outset that there was expected to be a human legacy as a result of the Games. This was articulated as:

the Games will also leave important human legacies generated from the participation of people in the Games..... The Games will help create an enhanced talent pool with new skills - in particular for people in the inner-city and Aboriginal communities. Some 25,000 volunteers will participate in the Games. This unique experience of 
contributing to an international event will create an enhanced talent pool of volunteers for $\mathrm{BC}$ and Canada and will provide increased awareness about the passion for and benefits of volunteerism across the country. (VANOC, 2007, p. 190)

From this we might assume that the legacy would flow from a combination of the design, implementation and operationalisation of training as well as the on-the-job experiences of the volunteers. What this does not articulate is the link back to the community groups who may be able to benefit from the volunteers' experiences and thus be part of the social legacy. This article considers how successful the extant model of training and development was for legacy across three research themes i) the rhetoric of training and legacy, ii) the reality of the volunteers' training experience and volunteer organisations' expectations and iii) volunteers' reflections twelve months after the Games. The following section outlines literature pertaining to training and event volunteers, followed by the research design and then the results which are subdivided to highlight the findings from the research themes. The final sections offer a Sport Event Legacy Training and Development Model, which is applied to the case study and discusses the findings and conclusions drawn from the research.

\section{Training event volunteers for legacy}

Considering the importance of volunteers for the successful delivery of mega sport events, combined with the rhetoric of a volunteer legacy over a number of Games (DCMS, 2012; Sochi 2014, 2009; VANOC, 2007) it may be expected that there would be significant literature on the achievement of a volunteer legacy. However as noted by Shaw (2009), much of the sport event volunteer research has been linked to motivation (e.g. Fairley, Kellett, \& Green, 2007) and job satisfaction (e.g. Costa et al. 2006) rather than the training, development or the transfer of knowledge/skills for legacy. 
Sport event volunteer training is situated within a broader literature on training and development in which the focus of training is upon the short-term achievement of jobspecific skills and abilities relevant to the current work situation, while development is more often focused upon future job needs (Garavan, 1997). In the event context, this would equate to training for the event delivery and development for legacy beyond the event including the transfer of training to other volunteer contexts. Best-practice examples of training transfer include job-relevant training; opportunities to apply the learning; supervisory and peer support in the workplace; and measurement and evaluation of the transfer and job-relevant training (Burke \& Hutchins, 2008). For example, training transfer may be facilitated when volunteers and community organisations have plans in place prior to the Games.

Bowdin, Allen, Harris, McDonnell and O'Toole (2012) suggested that 'training and professional development are significant in driving the success of an event, acting to underpin its effective delivery' (p. 344). Their distinction between training and professional development coincides with Garavan's (1997) view that training is related to current job performance, i.e. the event, whilst development is about preparation for the future, i.e. legacy. For the training to be most effective Bowdin et al., (2012) suggests that a training needs analysis be conducted in order to 'determine the gap between the current performance of staff and volunteers and their desired performance [and then to] determine whether the training taking place is adequate and whether any training needs are not being met' (p. 344). In terms of legacy this would mean that training and development would need to be focused not only upon knowledge and skills required for Games delivery, but also for supporting the creation of a volunteer legacy for community organisations beyond the event. 
Costa et al. (2006) asserted that most training occurs prior to the event, in contrast to Bowdin et al. (2012) who suggested that, because events are generally sporadic and of a short duration, most training would be on-the-job.. Regardless of the timing, the training literature would suggest that in to be effective, particularly in relation to training transfer those conducting the training must be skilled and experienced in training and development and, in particular, conducting needs assessment, delivering training using adult learning theories and evaluating the outcomes (Burke \& Hutchins, 2008; Costa et al., 2006; Knowles, Holton and Swanson, 2011). Moreover, the training delivery team will need to have the capacity to enable appropriate knowledge acquisition, through well-designed learning interventions as time will be short and there will be little opportunity to repeat learning opportunities.

When considering the evaluation of training a well-known model was proposed by Donald Kirkpatrick (1959) which has been applied in a sport event context (Costa et al., 2006). The four levels of evaluation are: 1) reaction, or satisfaction, of the trainees to the training, e.g. a 'happy sheet'; 2) learning: skills and/or knowledge acquired; 3) behaviour changes seen in the workplace as a result of the training being transferred; and 4) results in other areas such as productivity, cost reductions or absenteeism that may be a consequence of the training. In addition to receiving feedback about the volunteers' training experiences (level 1), to begin to measure whether there is a social legacy of events, one would at least expect to see evaluation of learning (level 2), but also to see evaluation of behaviour changes in the broad context of volunteering (level 3). Additionally, given the large public investment in these events, one might also expect to see some significant work towards evaluation of results, such as increased volunteering levels (level 4). Data from the Games was analysed to determine not only what type of training was undertaken but also what forms 
of evaluation were use to gauge the training success. From this the likely success of the training for long term change could be assessed.

\section{Research design}

This study is part of a larger research project (references witheld due to anonymity) that was undertaken on the Vancouver 2010 Winter Olympic and Paralympic Games. Prior approval for this research was obtained from the International Paralympic Committee Sports Science Committees and three Universities' Ethics Committees. A case study approach was used which is appropriate where the observer has access to a novel, previously unexplained phenomenon thus enabling in-depth investigation into a specific set of circumstances in a particular context (Yin, 2002). Data for this article was gathered from five sources: documentary analysis; volunteer interviews; participant observation; workshop with community groups and a post-games survey.

\section{Documentary analysis}

Analysis was undertaken of the following VANOC's documents was conducted prior to and throughout the event:

My Games Training folder for alpine crews at Whistler Creekside including:

- Team 2010 Orientation manual

- Service Excellence Manual

- Job Specific Training Booklet for Alpine Skiing

- Venue Specific Training Booklet Whistler Creekside

- Venue Specific Training Booklet Whistler Creekside Paralympic Supplement 
- Venue Specific Training Booklet Whistler Olympic Park

Training manuals and resources:

- VANOC (2008a) My Games Training, Vancouver 2010 Olympic and Paralympic Winter Games, Participant's Guide.

- VANOC (2008b) The Olympic and Paralympic Games: Team 2010 Orientation, Special Partners Training, Trainer's Guide.

- VANOC. (2010). Staging the Olympic Winter Games Knowledge Report

- Service Excellence Training Manual

- Event Leadership Training Manual

- WorldHost ${ }^{\mathrm{TM}}$ Training Services Ambassadors Program Trainers Guide

- On Your Mark Website

- WorldHost $^{T M}$ Training Services Ambassador Program Training Manual

Other planning resources:

- RMOW. (2008). Delivering the dream: Whistler - host mountain resort, 2010 Olympic and Paralympic Winter Games.

- Vancouver 2010 Bid Corporation. (2002). The Vancouver 2010 Bid Books, Vols 1-3.

- VANOC. (2007). Business Plan and Games Budget. Vancouver: Vancouver Organizing Committee for the 2010 Olympic and Paralympic Winter Games.

\section{Interviews with volunteers}

Semi structured in-depth interviews were undertaken with 38 volunteers across a range of functional areas in February and March, during the 2010 Games. The interviewees were recruited initially as a result of a larger online survey, this then developed into a snowball sample through networks and referrals from previously interviewed respondents. Interviews ranged from 20 minutes to one hour 40 minutes. 


\section{Participant observation}

One of the authors participated in all of the training offered in the lead-up to the Games and participated with volunteers on-hill at the alpine venue during the Olympic and Paralympic alpine events. Two of the other authors observed a Venue Specific Training session at the cross-country ski venue, Whistler Olympic Park. .

\section{Workshop with host community volunteer organisations}

A workshop around the theme of legacy was conducted by one of the authors six months after the Games at the 'Volunteer BC 2010' Conference, where representatives from approximately thirty community volunteer organisations attended. The participants formed seven tables, each table consisting of a mixed group of community stakeholders. Each table was asked to consider the five questions in Figure 1.

Figure 1 about here

\section{Post-Games survey}

The post-games online survey investigated the volunteers' reflections upon their experiences of training. While this was distributed widely using a snowball sampling technique through VANOC's database, email contacts, and Vancouver 2010 Volunteer Facebook groups, the response was quite low given that 19,104 people had volunteered for the Games. Of the 219 responses, $178(81 \%)$ were VANOC volunteers, the others had volunteered in other roles during the Games. Despite VANOC's assertion that there was an effective database of volunteers after the Games (VANOC, 2010a), it was clear from this survey that the database was not accurate nor an effective communication tool to volunteers. 


\section{Results}

This section outlines the results across the three key research themes outlined in the introduction:

\section{The rhetoric of training and legacy}

The rhetoric of a volunteer legacy dates back to the original bid through to reporting after the Games. The Vancouver Whistler 2010 Bid Corporation was established in June 1999 when the Canadian Olympic Committee chose the City of Vancouver and the Municipality of Whistler as its choice to bid on the 2010 Olympic and Paralympic Winter Games (VANOC, 2009). As part of the bid the corporation indicated that the social and community impacts of the Games would include education, training and volunteer development (Vancouver 2010 Bid Corporation, 2002).

This rhetoric continued with the Vancouver Organizing Committee (VANOC) which emerged from the bid corporation when, in 2003, Vancouver and Whistler were chosen by the International Olympic Committee to host the 2010 Games. For the host community of Whistler, their expectation was that "'Skills, capacity and learning development will result from Whistler residents' involvement and volunteering with the Games, and will be transferable to other elements of community-building and economic opportunities" (RMOW, 2008, p. 31). It was this expectation that was the impetus for the authors' overall research program on volunteer legacies.

In the post-games knowledge report it was stated that: 
With the Games experience now in the rear-view mirror, the hope is that the history, values and spirit of the Games have created a passion for volunteerism in BC and Canada. Working with 2010 Legacies Now, VANOC created a database of volunteers who consented to having their contact information passed on to other community-based organizations seeking volunteers. Ideally, this will result in thousands of "new" volunteers taking on a wide range of roles at future events in British Columbia and elsewhere in Canada, resulting in a positive and enduring Games legacy. (VANOC, 2010a, p. 40)

\section{The reality of the volunteers' training experience and volunteer organisations' legacy expectations}

Recruitment and training needs analysis

VANOC's Department of Human Resources, Sustainability and International Client Services (colloquially known as 'Workforce') was charged with hiring and training the 1,400 staff and the estimated 25,000 volunteers, as well as for 10,000 contractors and 15,000 ceremony participants, bringing the workforce total to 55,000 (VANOC, 2007, 2010b). VANOC intended that a community legacy of the Games was to be an 'an enhanced talent pool of volunteers for BC and Canada,' (VANOC, 2007, p. 36) and this department had the responsibility to support that outcome including both recruitment and training phases.

Recruiting enough individuals with the appropriate skills and abilities and sufficient time and commitment is a major challenge for volunteer recruitment committees in small to medium sized sport events (Cleave \& Doherty, 2005), but it may be even more challenging with mega sport events given the scale of the recruitment process. By 2009 VANOC had 
received over 60,000 volunteer applications (VANOC, 2010b) who then went through an initial application; telephone screening; a security check with the Royal Canadian Mounted Police; a face-to-face interview; and then the orientation and service training, all of which preceded the final selection process.

While there was no individualised training needs analysis that one might expect in other smaller event training contexts (Bowdin et al., 2012), the recruitment process acted as a filter that minimised the gap between the required skills and the training that was to be provided. Even for the sport volunteers who had to meet minimum skills and qualification requirements, they all still had to participate in the same training regardless of their prior knowledge or skill base.

\section{Training design}

An examination of the VANOC training material indicated that they aimed to draw upon the best information available about adult learners and how they learn (e.g. Caffarella, 2001; Apps, 1989). Train-the-trainer materials included theories regarding adult learners, learning climates, learning styles, multiple intelligences and facilitation techniques. (VANOC, 2008 a, b). The intention to underpin the volunteer training with pedagogic research was clearly evident.

The volunteer training consisted of:

- Creating Team 2010: Orientation and Service Excellence training

- Legacy of Safety Awareness training (VANOC, 2010b)

- Job specific training

- Venue-specific training 
- Event Leadership (VANOC, 2008a, b)

This training was considered mandatory and failure to complete it could put the volunteers' position in jeopardy (VANOC, 2010c).

The Orientation and Service Excellence training was offered up to 18 months prior to the Games and took place in one day aiming to inspire, engage and motivate individuals towards hosting an extraordinary Olympic and Paralympic Games. The Service Excellence training highlighted the commitment of VANOC and Tourism BC to service excellence at every point of the guest experience. This training had generic service themes drawn from WorldHost ${ }^{T M}$ training relevant to other volunteering contexts.

Job-specific training related directly to the duties assigned to volunteers with experts in each area developing and delivering training specific to their functional area. All Games volunteers undertook venue-specific training geared to understanding the operation of the venue to which they were assigned during Games time including venue layout, workspaces, safety and emergency procedures. While most of this training was specific to the Games, the safety themes may also be applicable in other contexts. Event Leadership training was for those in leadership roles and focused on: accountability, leadership, communication, leadership philosophies in harmony with the Games and best practices for leading volunteers (VANOC, 2008).

In addition to the face-to-face training VANOC volunteers had access to the "On Your Mark" extranet (see Figure 2), a password protected site for VANOC volunteers that was both a communication tool and a tracking device for volunteer training. This was the first time that a 
significant e-learning experience had been made available for Olympic or Paralympic volunteer training. The nine sections could reinforce some of the face-to-face training. While a great innovation, from the perspective of best practice in training and development there were four mistakes in its implementation if VANOC was hoping to contribute to a volunteer legacy via best-practice training. Firstly, there was no prior knowledge assessment; secondly, while the website had tracking ability it was not used and there were no records of who accessed the information, for how long and what sections were undertaken; thirdly, while 'knowledge checks' were great tools for the volunteers themselves, there was no recording of these at the end of each section that could contribute to a credentialing or certification process and finally, there was limited evaluation of the training experience.

Figure 2 about here

\section{The Training Experience}

The volunteers' awareness or retention of their training was varied, which may be a result of the fact that, for some, training occurred up to 18 months prior the Games in order to be prepared for test events as well as the training forming part of the on-going selection process. Examples of volunteers' observations are:

Lots!: about 40 hrs: initially welcoming, cultural sensitivity raising, became more specific got to point, brought around to various venues, then put into the cars, came up to Whistler; confidentiality about what you heard in the car (Female, $67 \mathrm{yrs,}$ Assistant International Client Services driver) 
Very little; nothing on customer service; not much needed for load zone (buses) ... technical no, not many people would come looking to advancing their technical skills; human relations, yes; received written info in how to deal with the public, what you should do, what you should not do, short orientation; opportunity for training was much more here (Vancouver), not expected to fly out for training. (Male, 57 yrs, Load Zone Attendant)

Not much: 2 trainings: what our jobs were all about (4 hrs); venue training (4 hrs): taken around the venues ... Got to know the venue well to answer questions; also taught us how to deal with people to deal with difficult situations (haven't seen too many of those, but it happens). (Female, 62 yrs, Host)

Further, some of the volunteers' reaction to their training was expressed in terms such as 'waste of time'; 'no flexibility'; 'done in less time'; 'not relevant' indicating the training they were given was not always valued or deemed appropriate. This may in part be a result of having experienced volunteers (e.g. Nordic and Alpine volunteers recruited for their sport expertise) taking part in introductory training sessions where trainers were unaware of the expertise in the room or may not have had the time or skill to deal with the audience diversity. The following volunteers' quotes highlight the levels of frustration with the training:

Venue specific was dumb, it was a waste of time, they did not know what they were talking about... I ski here all the time (Female, 47 years, Slipper: Women's Course)

Ridiculous venue-specific training is waste of time, ... VANOC does not understand management. Orientation: the hour was nonsense ... it got into some weird BC stuff, 
it was unprofessionally delivered ... it was not a business format ... they wanted to set the tone ... it's a business ... it needed to apply to what was actually going to happen (Male, 44 yrs, Alpine: Men's Course steward)

Venue specific training and job specific training, both of which are very limited information about the venue; amounted to 10mins of useful info squeezed into 2 hrs (Male, 63yrs, Nordic transponder)

...not all the training was relevant ... but you just didn't need 4 days .. they were expensive too, big venues, foods, big manuals, which I have not read. (Male, 44yrs, Nordic Anti-doping)

There is a mould and everyone has to use the mould, there is no flexibility....; (Female, Accreditation and Team Leader)

Volunteer responses indicated that as well as the formal training sessions and online training made available by VANOC, 'on the job' training, both formal and informal, was also evident. This was not generally perceived as negative with one volunteer even indicating it was the 'best training' he received:

Venue specific... learnt about the rules itself, taught along the way ... one guy ... who is very scary but who taught us to slip the course really well... (Female, $17 \mathrm{yrs}$, Alpine: Youth Slip Crew)

1 training session (orientation), mostly on-the-job. (Male, 73 yrs, Print Distribution, Sliding Centre) 
...doing one sport event was the best training I got ... the training led up to the sport event (Male, 44yrs, Nordic Anti-doping)

A binder full of information and a DVD (1 yr ago): a general orientation to the Olympics; then given brief training for the venue specific, but my time on the hill was cancelled due to the weather, I started work the next day, it was learn as you go ... My existing skills were all I needed to do the job (Female, 25 years, Alpine: Course Crew, [Previously raced, but never worked on courses])

Further, in a number of cases respondents indicated that it did not matter about the training as they had an existing skill set that enabled them to perform their volunteer role:

Venue specific training ... I think I already had the skills ... it properly refreshed everything, enhanced it a little more for this role; I probably could have done this role with very little training; using the skills I already had (Male, 49 years, NOC [ no previous experience as $\mathrm{NOC}]$ )

Venue specific (2hrs) and the 'gate judging training' (2hrs) ... they did not tell us anything we did not already know. However, there were some there who have never been gate judges... (Female, 61yrs, Alpine, Women's gate judge)

The focus upon safety and security training featured in volunteer responses, although this was received with mixed perceptions with some seeing it more as a compliance requirement of WorksafeBC than a knowledge or skill development process relevant to their role: 
...[training]..very poorly organised, appeared to be primarily concerned with safety issues ... getting down to liability; nothing specific to the venue... (Male, $51 \mathrm{yrs,}$ Alpine: Men's Course steward [1 $1^{\text {st }}$ time $]$ )

General training about what to do, how the course works, it was what are the security measures, if there is an incident who do you call ... Taught me way more what to do on the course, how to make the course safe for the racers; all the little things (Male, 20 yrs, Alpine Crew [1 $1^{\text {st }}$ time on Alpine Crew])

Safety Training was really horrifying: receiving a form and being told where the first aid office is, it should have gone further than that (Male, 63yrs, Nordic transponder)

....watch this safety video, sign and go up on the hill! (Female, 52 yrs, Alpine, Men's)

Whilst there are positive comments throughout the quotes, it is also clear that some volunteers had negative experiences impacted by the lack of recognition of prior learning, compliance requirements and/or the inflexibility of the training which may be due to the scale of the training, or the skills of the trainer. These comments must also be considered in light of the post-games survey discussed later.

\section{Evaluation}

Training evaluation reflects best practice if one is seeking to measure learning outcomes and training transfer; however there was little evidence from our research that this evaluation occurred. There were surveys after each training session that attempted to get at how volunteers felt about the training they had just completed (Kirkpatrick's (1959) level 1), but 
there was no evaluation of training regarding actual learning outcomes (Kirkpatrick's (1959) level 2) nor were there strategies to enhance transfer beyond the Games, as it was not part of the training agenda (Kirkpatrick's (1959) levels 3 and 4).

\section{Legacy reality}

Six months after the Game one of the authors conducted a workshop in Vancouver (September 2010) that provided insight into whether there was an environment that would support the transfer of learning to other volunteer contexts.

The involvement of young people from some communities as volunteers was seen as supporting a potential volunteer legacy, 'A lot of students in Surrey really put their hearts into volunteering and went en masse... that was a positive legacy because there are more kids interested in service to the community' (Workshop Table 6). This was tempered by the reality that of all those who attended the workshop, only one organisation had designed and implemented a plan for developing a volunteer legacy, as Workshop Table 4 responded, 'We didn't think of it, didn't know we were supposed to' while another stated 'I haven't seen so much of a legacy' and the crux of the issue was that, 'there are some new ideas and energy but it wasn't well harnessed. No one took advantage of those ideas'.

Some participants indicated that there were negative impacts of volunteering at the Games where they had seen what they considered burn-out among volunteers from the Games, while other volunteers had not returned to their pre-Games volunteering roles (Workshop Table 7). Another impact upon legacy was the change in expectations as a result of volunteering for Vancouver 2010, where 'A negative effect for some participants was that volunteers have new expectations now such as a good meal and short shifts' (Workshop Table 7). This is 
similar to an observation that 'We see the Games used to trigger excitement. But it's hard to reproduce that without all the media and everything anymore' (Workshop Table 4).

What is also evident from the workshop was that the community groups did not plan for legacy or, perhaps more importantly, realise that planning was necessary if they wanted to achieve a long-term impact. Organisations such as 2010 Legacies Now and VolWeb existed prior to the Games, yet their message had not effectively reached the volunteer community present. While the focus of VANOC was on delivering the Games, it may be suggested that had there been more communication about planning for legacy before the Games between VANOC and the community groups represented at this workshop, then the volunteer legacy potential may have been greater. Questions remain as to why the VolWeb and 2010 Legacies Now communication was not reaching this audience.

\section{Post-Games Survey: Volunteer's reflections 12 months after the Games}

The 219 volunteers in the post-games survey were mostly females $(63 \%)$, and older with the largest age group being 60-64 years (16\%) with only 6\% less than 25 years of age. Of the $219,15 \%(n=33)$ indicated that 12 months after the Games they were volunteering more, $15 \%$ were volunteering less, $64 \%$ the same, and $8 \%$ did not respond showing less than a $2 \%$ net increase in volunteering (i.e. those who indicated they are volunteering more, less those who indicated they are volunteering less). From a list of eight factors, those considered to be the most important for increasing the level of volunteering were: the feeling that they could make a difference (94\%), being able to give back to the community $(91 \%)$, a feeling of pride $(88 \%)$, the sense of community (77\%), the public celebration of volunteers $(64 \%)$, and the skills gained during the Games (61\%). These primarily reflect the altruism noted by Twynam et al. (2002). 
Volunteers were also asked to indicate to what extent they agreed with the statements about each training phase (outlined earlier) using a five point Likert scale ( $1=$ Strongly disagree to $5=$ Strongly agree). The mean for each statement (Table 1) indicate a high level of satisfaction across all areas of training, which is interesting when reflecting upon some of the volunteer quotes earlier. Further they provide insight into how the OSET supported the objective of getting people excited (mean=4.11) and connected with the Games (mean=4.16). Only 75\% of respondents indicated they used the online OYM training, which had the lowest overall rating (3.66), was least enjoyable (3.62), though many indicated it was still relevant (3.68) and supported their preparation (3.56). The Job Specific training had the highest overall rating (4.02) but was considered less enjoyable (3.90), but still helped developed connection (4.10) as well as preparing volunteers for the event (4.07). The Venue Specific training while interesting (3.92) also contributed to some volunteers feeling excited (4.01) and connected (4.02) to the Games.

\section{Table 1 about here}

\section{Discussion and the development of a model}

Prior to the Games VANOC stated that the goal of Games-time training (2008 a, b) was to touch and inspire the people who will be delivering on the VANOC mission by creating a positive and engaging learning experience for all participants and that the objectives included: equipping the VANOC workforce with the right skills, information and attitudes for success; building a sense of personal ownership for the success of the Games; fostering an intimate knowledge and passion for Vancouver, Whistler, BC, Canada and the Games; and serving as an ongoing selection tool to ensure that the right people are in the right places at 
the right times. VANOC was hoping for: an engaged and inspired workforce; Gamespassionate people who are ready to work to create an extraordinary Games experience; and an informed and skilled workforce with the leadership, technical and interpersonal aptitude necessary for success (VANOC $2008 \mathrm{a}, \mathrm{b}$ ).

When considering the legacy expectations, and the process and content of the training as revealed through the documentary analysis, it would appear that with the necessary focus upon event delivery and event schedules the actual training was mostly focused upon the specifics of the task, with lesser emphasis upon the relevance and the transfer of that knowledge to other contexts after the Games.

The orientation, job specific training and venue specific training were focused upon tasks related to the event delivery with minimal transferability given the content that needs to be conveyed for the event delivery. In contrast, the service excellence and event leadership had a much greater potential to offer professional development opportunities and therefore, be transferred to another context and thus support a potential volunteer legacy. Nevertheless, the extent to which training contributed to a human legacy corresponding to the rhetoric is less clear and suggests a missed legacy opportunity.

The volunteers' insights during the Games regarding their training experience provides mixed messages as to the extent the training was meeting the expectations and needs of the volunteers, in contrast the findings from volunteers' twelve months on suggests that their training did reflect the recruitment and training of an inspired workforce that delivered a world-class Games; however, this does not equate to a volunteer legacy. What may be missing from the Games planning is the longer-term plan that clearly operationalizes the 
objectives for a volunteer legacy and includes communication with relevant legacy partners as implied in the responses from the workshop participants six months after the Games.

Drawing upon the literature and the results presented a Sport Event Legacy Training and Development Model has been devised (Figure 3), which builds upon examples of best practices of events training and development (e.g. Bowdin et al., 2012; Burke \& Hutchins, 2008; Costa et al., 2006; Kirkpatrick, 1959) in order to capture the elements that would be required to deliver on both the event and the legacy agendas.

Figure 3 about here

Table 2 summarises the research findings from this case study against the Legacy Training and Development Model developed in this paper (Figure 3) in order to evaluate the extent to which aspects of the model were identified (indicated by a tick) or clearly absent (indicated by a cross) in data sources from this case study. Gaps in the table indicate that there was no clear evidence one way or the other.

Table 2 about here

When considering the evidence presented here, the major gaps in the system include:

- Lack of training transfer planning (pre or post) that would support a volunteer legacy such as co-ordination and communication with those organisations who may benefit most from a volunteer legacy;

- No individualised training needs analysis or recognition of prior learning; 
- Training focused predominantly upon event delivery and not event legacy;

- Insufficient evaluation (element 6) of training across levels 2 and 3 that could demonstrate or inform a legacy outcome (Kirkpatrick, 1959).

\section{From Vancouver 2010 to London 2012 and beyond}

The findings from Vancouver 2010 suggests that the training and experiences of the volunteers, while supporting the delivery of the Games, did little to enhance a volunteering legacy for a wider social context and that this may be a missed opportunity. It is easy to see a similar pattern for London 2012. Through the bid process the UK government and the organising committee (LOCOG) have made claims of a wider social legacy with volunteering at its core. Now the London 2012 Games are over, they are being hailed as the 'legacy Games' however, in the context of volunteering it would appear that there is, once again, some disconnect over the extent to which this legacy will be realised. Justin Davis-Smith, Chief Executive of Volunteering England, in a September 2012 news release states "The volunteers were the astonishing success of the Olympic and Paralympic Games..... The question now is what happens next. $\quad$.... Is it realistic to expect a lasting legacy to be achieved, ...". He continues by outlining three key lessons that stand out (1) leadership with 'volunteering being championed from the top' and 'essential to the delivery of the project itself"; (2) Recognition of the volunteers and (3) the most challenging, the issue of investment 'volunteering requires investment and support to make it work'. His final comment of the news release highlights that, '....without investment the dream of a lasting legacy from the Games will remain just that' (Davis-Smith, 2012: np). This is further supported by Terry Ryall, Chief Executive of vInspired ${ }^{\mathrm{i}}$ who in her Blog just after the 
London 2012 Games stated "Wouldn't it be great to have a national driver with a simple vision for a volunteering legacy that we can feel part of, and that can co-ordinate our efforts of the voluntary sector so we can all do our bit for the bigger picture? I hope sincerely that someone somewhere has been beavering away and I can't wait for the big reveal!" (Ryall, 2012: np). Investment may not just be about money, but it may also be time, expertise and revised visions that go beyond the Games, but in each of these quotes the discussion is happening after the Games are over, not in the lead-up when planning, communication and resourcing may occur.

The rhetoric of volunteering legacy is also characterised the preparatory phases for the Games of Sochi 2014 in Russia and Rio 2016, Brazil. The organising committees of the Sochi 2014 Games said that they aimed to develop a pool of volunteers as a resource beyond the Games drawing upon young volunteers across Europe to unite them under the values of Olympism. Dmitry Chernyshenko, the Sochi 2014 President and CEO, suggested that 'Our programme to train volunteers will not only deliver skilled and enthusiastic volunteers to welcome the world to Sochi in 2014, but also leave the invaluable legacy of a volunteering culture in Russia which will benefit the nation for years into the future'(Sochi 2014, 2011). Henrique Gonzalez, Human Resources Director of the Rio 2016 organising committee stated: The main legacy will be training people to organise sporting events in another level of professionalism and to deliver excellence. .... The workforce we will have here will develop according to the best management practices, which contribute to their leadership capacity, to face transformational challenges, planning, management and operation. These professionals will also leave this experience better qualified to face the corporate job market. (Rio 2016, 2013:np). 
Whilst it is clear that some of the official discourses continue with the rhetoric of a volunteering legacy, what is important here, is to what extent will the 'missed opportunity' to deliver on this still be evident, in say 2017, one year after the Rio 2016 Games. Or finally, will future OCOGs understand that planning for volunteer legacy is just as important as planning for volunteers in respect of delivering the Games? That planning may include communication, co-ordination with, and potentially training of, those organisations that may benefit from a post-Games volunteer legacy.

\section{Conclusion}

From the bid through the planning and delivery of mega events, legacies are part of the discourse, particularly with respect to the social or human capital legacy related to volunteers. However, this paper suggests that there is a 'legacy gap' between the rhetoric and the reality in achieving a volunteering legacy, and that a key aspect of this is the planning, design and execution of training in terms of a best practice model for delivering both the Games and development (legacy) opportunities. We argue that, in line with the training and development literature pertaining to effective knowledge acquisition and transfer of training into a new workplace or context, legacy will only occur when the required long-term learning outcomes have been identified, developed into the training plan and delivered in an appropriate manner in partnership with relevant organisations, such as the community organisations who may benefit from the volunteer legacy. This will necessitate a much more careful assessment of the desired human legacy which will, of itself, enable increased awareness of the requirements to support legacy development, the time frame for planning for and delivering legacy and the relevant partners in the legacy creation program. 


\section{References}

Apps, J. (1989). "Providers of Adult and Continuing Education: A Framework." Handbook of Adult and Continuing Education. San Francisco: Jossey-Bass.

Bowdin, G., Allen, J., Harris, R., McDonnell, I., \& O'Toole, W. (2012). Events Management: Taylor \& Francis.

Burke, L. A., \& Hutchins, H. M. (2008). A study of best practices in training transfer and proposed model of transfer. Human Resource Development Quarterly, 19, 107-128.

Caffarella, R. S. (2001). Planning programs for adult learners: A practical guide for educators, trainers, and staff developers (2 ed.). San Francisco: Jossey-Bass, Inc.

Cleave, S. L. \& Doherty, A (2005). "Understanding volunteer and non-volunteer constraints: A mixed-method approach". Presented at the 11th Canadian Congress on Leisure Research, May 17 - 20, 2005 Nanaimo, BC

Costa, C. A., Chalip, L., Green, B. C., \& Simes, C. (2006). Reconsidering the role of training in event volunteers' satisfaction. Sport Management Review, 9, 165-182.

Davis-Smith, J. (2012). The volunteering legacy of London 2012. Posted 27 September 2012 fromhttp://www.volunteering.org.uk/aboutus/news-releases/2354-the-volunteeringlegacy-of-london-2012

Department for Culture Media and Sport. (2012). Beyond 2012: the London 2012 legacy story. In. London: Department for Culture, Media and Sport.

Dickson, T. J., Benson, A. M., \& Blackman, D. A. (2011). Developing a framework for evaluating Olympic and Paralympic legacies. Journal of Sport and Tourism, 16(4), 285-302.

Dickson, T. J., Benson, A. M., Blackman, D. A., \& Terwiel, A. F. (2013). It's All About the Games! 2010 Vancouver Olympic and Paralympic Winter Games Volunteers. Event Management, 17(1), 77-92. doi: 10.3727/152599513x13623342048220

Dickson, T. J., Terwiel, F. A., \& Benson, A. M. (2011). Volunteers of the 2010 Olympic and Paralympics Winter Games: Lessons for the future. Paper presented at the IV International Conference: "Education and training for the XXII Sochi 2014 Winter Olympic and Paralympic Games: Challenges and solutions", 24-25th October, Sochi.

Fairley, S., Kellett, P., \& Green, B. C. (2007). Volunteering abroad: Motives for travel to volunteer at the Athens Olympic Games. Journal of Sport Management, 21, 41-57.

Farrell, J. M., Johnston, M. E., \& Twynam, G. D. (1998). Volunteer motivation, satisfaction, and management at an elite sporting competition. Journal of Sport Management, 12, 288-300.

Furlong, J. (2010). John Furlong Closing Ceremony Speech. In CTV News. Vancouver.

Garavan, T. N. (1997). Training, development, education and learning: different or the same? Journal of European Industrial Training, 21, 39-50.

Kirkpatrick, D. L. (1959). Techniques for evaluating training programs. Journal of the American Society of Training Directors, 13, 3-26.

Knowles, M.S., Holton, E.F. and Swanson, R.A. (2011). The Adult Learner: The Definitive Classic in Adult Education and Human Resource Development. Oxford: UK; Oxford UK.

MacAloon, J. (2000) Volunteers, Global Society and the Olympic Movement. In M. de Moragas, A.B. Moreno and N. Puig (eds) Volunteers, Global Society and the Olympic Movement. International Sympoisum Lausanne, 1999 (pp. 17-29). Lausanne: International Olympic Committee. 
Rio 2016. (2013). An interview with Henrique Gonzalez, Human Resources Director of the Rio 2016 ${ }^{\mathrm{TM}}$ Organising Committee. Available at:

http://rio2016.com/en/news/interviews/henrique-gonzalez

RMOW. (2008). Delivering the dream: Whistler - host mountain resort, 2010 Olympic and Paralympic Winter Games. Whistler: Resort Municipality of Whistler.

Ryall, T. (2012). London2012: harnessing the energy of volunteers is key to legacy. Posted 13 August 2012 at http://vinspired.org/blog/london-2012-how-can-we-harness-theenergy-of-volunteers-going-forward

Shaw, S. (2009). "It was all 'smile for Dunedin!"': Event volunteer experiences at the 2006 New Zealand Masters Games. Sport Management Review, 12, 26-33.

Sochi 2014. (2009). Motivation - Sochi 2014 Candidature File - Our bid - Sochi 2014. In (May ed.). Sochi: Organizing Committee of the XXII Olympic Winter Games and the XI Paralympic Winter Games of 2014 in Sochi,.

Sochi 2014. (2011). Sochi 2014 Announce European Volunteering Initiative. In: Organizing Committee of the XXII Olympic Winter Games and XI Paralympic Winter Games of 2014 in Sochi. Available at: http://www.sochi2014.com/en/media/news/39554/

Strigas, A. D., \& Newton-Jackson Jr, E. (2003). Motivating volunteers to serve and succeed: design and results of a pilot study that explores demographics and motivational factors in sport vounteerism. International Sports Journal, 7, 111-123.

Twynam, G. D., Farrell, J. M., \& Johnston, M. E. (2002). Leisure and volunteer motivation at a special sporting event. Leisure/Loisir: Journal of the Canadian Association for Leisure Studies, 27, 363-377.

Vancouver 2010 Bid Corporation. (2002). The Vancouver 2010 Bid Books, Vols 1-3. Vancouver: Vancouver 2010 Bid Corporation.

VANOC. (2007). Business Plan and Games Budget. In (May ed.). Vancouver: Vancouver Organizing Committee for the 2010 Olympic and Paralympic Winter Games.

VANOC. (2008a). My Games Training, Vancouver 2010 Olympic and Paralympic Winter Games, Participant's Guide. Vancouver Organizing Committee, Vancouver, BC, Canada.

VANOC. (2008b). The Olympic and Paralympic Games: Team 2010 Orientation, Special Partners Training, Trainer's Guide. Vancouver Organizing Committee, Vancouver, BC, Canada.

VANOC. (2009). Vancouver 2010 Bid Report. In. Vancouver: Vancouver Organizing Committee for the 2010 Olympic and Paralympic Winter Games.

VANOC. (2010a). Staging the Olympic Winter Games Knowledge Report. In. Vancouver: The Vancouver Organizing Committee for the 2010 Olympic and Paralympic Winter Games.

VANOC. (2010b). Vancouver 2010 Sustainability Report 2009-10. In. Vancouver: Vancouver Organizing Committee for the 2010 Olympic and Paralympic Winter Games.

VANOC. (2010c). Vancouver 2010 Workforce Portal - On Your Mark. In. Vancouver: The Vancouver Organizing Committee for the 2010 Olympic and Paralympic Winter Games.

Yin, R. K. (2002). Case study research, design and methods. Thousands Oaks, CA: SAGE Publications. 
ivInspired is a charity that helps young people discover the value of volunteering - for themselves and for others 